\title{
Electrochemical Determination of Letrozole in Pharmaceutical Formulations by Advanced Voltammetric Techniques
}

\author{
ANUBHA SHARMA, K. K. JHANKAL and D. K. SHARMA*
}

Electrochemical Research Laboratory, Department of Chemistry, University of Rajasthan, Jaipur (Rajasthan)- 302004, India

sharmadkuor@gmail.com

Received 21 September 2016 / Accepted 10 October 2016

\begin{abstract}
Electrochemical studies of letrozole by voltammetric techniques were carried out. The letrozole gave one well-defined reduction peak at $-0.4 \mathrm{~V}$ to $-0.5 \mathrm{~V} v$ s. $\mathrm{Ag} / \mathrm{AgCl}$ electrode in Britton Robinson buffer BR of $\mathrm{pH}$ 7.0. Under optimized conditions, a linear response was obtained between $3.5 \times 10^{-6} \mathrm{M}$ and $1.0 \times 10^{-4} \mathrm{M}$ in aqueous media for square wave and differential pulse cathodic adsorptive stripping voltammetric techniques. The electrochemical process was diffusion controlled. The value of limit of detection (LOD) were $3.77 \times 10^{-7} \mathrm{~mol} \mathrm{~L}^{-1}$ and $2.52 \times 10^{-7} \mathrm{~mol} \mathrm{~L}^{-1}$ for SWCAdSV and DPCAdSV respectively.
\end{abstract}

Keywords: Letrozole, Anti-Cancer, Cyclic voltammetry, Glassy carbon electrode, Square wave voltammetry

\section{Introduction}

Letrozole 4,4'-((1H-1,2,4-triazol-1-yl)methylene)dibenzonitrile (Figure 1), belongs to a group of anti-cancer drugs used in treatment of breast cancer and it is hormonally responsive after surgery. The mechanism of action of letrozole is as an Aromatase Inhibitor ${ }^{1-3}$. Letrozole is a nonsteroidal inhibitor of estrogen synthesis with antineoplastic activity ${ }^{4-6}$. As a third-generation aromatase inhibitor, letrozole selectively and reversibly inhibits aromatase, which may result in growth inhibition of estrogen-dependent breast cancer cells. Aromatase, a cytochrome $P-450$ enzyme localized to the endoplasmic reticulum of the cell and found in many tissues ${ }^{7-9}$.<smiles>N#Cc1ccc(C(c2ccc(C#N)cc2)n2cncn2)cc1</smiles>

Figure 1. Chemical structure of letrozole 
Several methods have been reported for the determination of letrozole which include reverse phase extraction, chromatography, LC-MS, high performance liquid chromatography (HPLC), solid phase extraction (SPE) and salting out liquid extraction ${ }^{10-12}$. Although spectrophotometry and chromatography are most commonly used techniques, but these reported methods for the determination of letrozole required pretreatment and timeconsuming extraction or evaporation steps prior to the analysis and are not sufficiently sensitive for convenient application to pharmaceutical formulations to final analysis ${ }^{13-23}$.

The purpose of the present work was to study the voltammetric reduction behaviour of letrozole by employing different voltammetric techniques and to establish the methodology for their trace determination by using square-wave cathodic adsorptive stripping voltammetry (SWCAdSV) in pharmaceutical formulation.

\section{Experimental}

Letrozole was purchased under the trade name Femara and was used after purification. The purification of the drug by the centrifugation and filtration process. A stock standard solution of bulk letrozole $\left(1.7 \times 10^{-4} \mathrm{~mol} \mathrm{~L} \mathrm{~L}^{-1}\right)$ was prepared in ethanol and preserved at $4{ }^{\circ} \mathrm{C}$ until assessment. A series of BR buffer of $\mathrm{pH}$ values 3.4 to 13 was prepared and used as a supporting electrolyte. Deionised water was used to prepare all the solutions. The working solutions were prepared by a fix volume of stock solution and buffers. Reagents were used of analytical grade.

\section{Instrumentation}

Employment for electrochemical techniques Model 1230A (SR 400) electrochemical analyzer (CHI Instrument TX, USA), with a totally automated attached to a PC with proper CHI 100W version 2.3 software for total control of the experiments and data collection and treatment. A cell system containing three electrodes was used with working electrode as activated glassy carbon electrode, reference electrode as $\mathrm{Ag} / \mathrm{AgCl}(3 \mathrm{M} \mathrm{KCl})$ and auxiliary electrode as the platinum wire. A digital pH-meter (CHINO- DB-1011) fit with a glass electrode standardized with buffers of known $\mathrm{pH}$ was used for measuring the $\mathrm{pH}$ values of the solutions.

\section{General procedure}

For total $10 \mathrm{~mL}$ solution, BR buffer of $\mathrm{pH} 7.0$ and the appropriate concentration of the letrozole were introduced into the electrochemical cell and purged with pure deoxygenated nitrogen for 10-15 minutes under stirred conditions. These results to remove oxygen gas before measurements. Electrochemical pre-treatment was always performed in the same solution in which the measurement was subsequently carried out. The working glassy carbon electrode was polished $0.05 \mu \mathrm{m}$ aluminium oxide and sonicated for a short time to remove impurities on the electrode surface and then it was dried in an oven at $40{ }^{\circ} \mathrm{C}$. The accumulation of letrozole at the working electrode was carried out for 15 to 20 seconds while the solution was stirred at $2000 \mathrm{rpm}$. After optimization of operational parameters the cyclic voltammogram and square wave cathodic adsorptive stripping were recorded.

\section{Results and Discussion}

Electrochemical study of letrozole was performed by using cyclic voltammetry, square wave cathodic absorptive stripping voltammetry (SWCADSV) and differential pulse cathodic adsoptive stripping voltammetry (DPCADSV). In all electrochemical methods letrozole gave one well defined reduction peak at $-0.46 \mathrm{~V}(\mathrm{Ag} / \mathrm{AgCl})$. 


\section{Cyclic voltammetric behaviour}

The cyclic voltammogram of letrozole in Britton Robinson buffers (pH 3.4-13.0) exhibits one well-defined reduction peak in the potential range of 0 to $-0.8 \mathrm{~V}$ versus $\mathrm{Ag} / \mathrm{AgCl}$ reference electrode at concentration $1.8 \times 10^{-6}$ and scan rates $50-150$. No peak could be observed in the anodic direction of the reverse scans, suggesting the irreversible nature of the electrode process.

\section{Effect of scan rate}

The voltammetric investigations at various scan rates were performed under the optimum conditions (Figure 2). As the scan rate increases gradually from the range 50 to $150 \mathrm{mV} / \mathrm{s}$ at fixed concentration of letrozole, the background signal decreases and peak potential is shifted towards a more negative value with increase in current confirming the irreversible nature of the reduction process. Furthermore, peak current (Ip) was found to be linearly dependent on square root of scan rate related with the Randles - Sevcik equation, which can be expressed $\mathrm{as}^{24,25}$ :

$$
\mathrm{Ip}=\left(2.99 \times 10^{5}\right) \mathrm{n}[\alpha \mathrm{n}]^{1 / 2} \mathrm{~A} \mathrm{C}_{\mathrm{o}} \mathrm{D}_{\mathrm{o}}^{1 / 2} v^{1 / 2}
$$

Where $\mathrm{n}$ is the number of electrons exchange in reduction, $\alpha$ is the charge transfer coefficient, $\mathrm{A}\left(\mathrm{cm}^{2}\right)$ is the apparent surface area of the electrode, $\mathrm{C}_{\mathrm{o}}(\mathrm{mol} / \mathrm{L})$ is the concentration of the electro-active species, Ip $(\mu \mathrm{A})$ is the cathodic peak current, $\mathrm{D}_{\mathrm{o}}\left(\mathrm{cm}^{2} / \mathrm{s}\right)$ is the diffusion coefficient of the electroactive species and $v(\mathrm{mV} / \mathrm{s})$ is the scan rate.

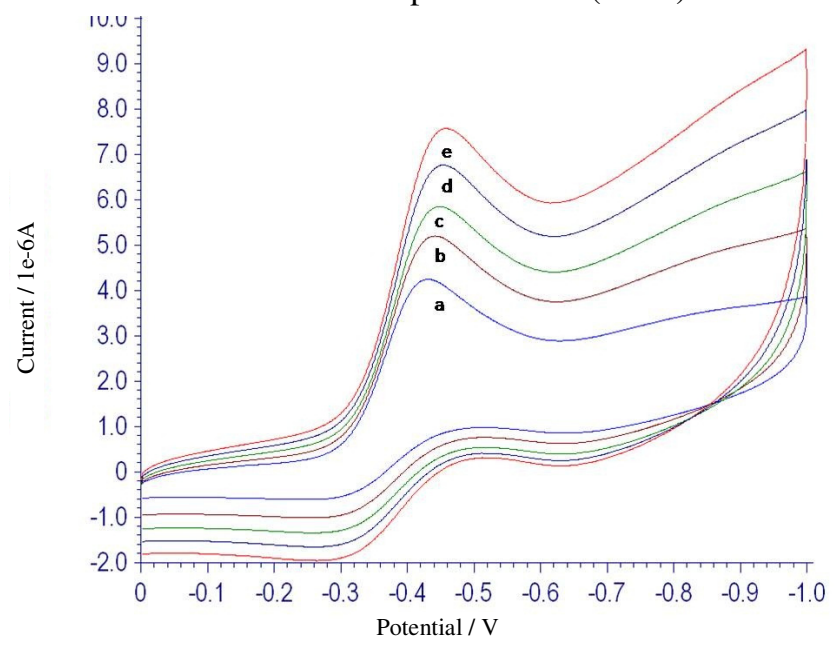

Figure 2. Cyclic voltammogram of $1.8 \times 10^{-6} \mathrm{molL}^{-1}$ Letrozole in Britton-Robinson buffer at different scan rates: (a) $50 \mathrm{mV}^{-1}$ (b) $75 \mathrm{mV}^{-1}$ (c) $100 \mathrm{mV}^{-1}$ (d) $125 \mathrm{mV}^{-1}$ (e) $150 \mathrm{mV}^{-1}$ at $\mathrm{pH} 7.0$

A graph between peak potential $(\mathrm{Ep} / \mathrm{V})$ versus logarithm of scan rate $(\log v)$ were plotted (Figure 3). A straight line was observed having a slope 0.057 when peak potential $(\mathrm{Ep} / \mathrm{V})$ was plotted against $\log v\left(\mathrm{mVs}^{-1}\right)$ at $\mathrm{pH}$ value of 7.0 and at a concentration $1.8 \times 10^{-6}$ can be expressed by the equation

$$
\mathrm{Ep}=0.057 \log v+0.339(\mathrm{~V}) \mathrm{R}^{2}=0.996
$$

Further, A graph between peak current (Ip) versus square root of scan rate $\left(v^{1 / 2}\right)$ were plotted (Figure 4). Again a straight line was observed in this plot at concentration $1.8 \times 10^{-6}$ and $\mathrm{pH} 7.0$, which may be expressed by the equation

$$
\operatorname{Ip}(\mu \mathrm{A})=0.357 v^{1 / 2}(\mathrm{mV} / \mathrm{s})+1.932(\mu \mathrm{A}) \mathrm{R}^{2}=0.991
$$


The effect of scan rate $\left(v^{1 / 2}\right)$ on peak current (Ip) was examined. As the scan rate was increased from 50 to $150 \mathrm{mVs}^{-1}$ at $1.8 \times 10^{-6}$ concentration of letrozole, the peak current increased steadily and the peak current function $\left(\mathrm{Ip} / \mathrm{v}^{1 / 2}\right)$ exhibited nearly constancy ${ }^{26,27}$.

The linear relationship existing between peak current (Ip) and square root of the scan rate $\left(v^{1 / 2}\right)$ with a slope 0.357 , showed that the reduction process is predominantly diffusion controlled in the whole scan rate range studied.

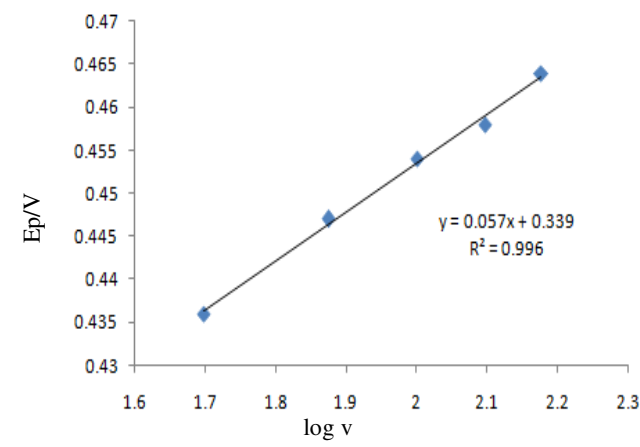

Figure 3. Plot of peak potential $(\mathrm{Ep} / \mathrm{V}) v s$. Logarithm of scan rates $\log v$

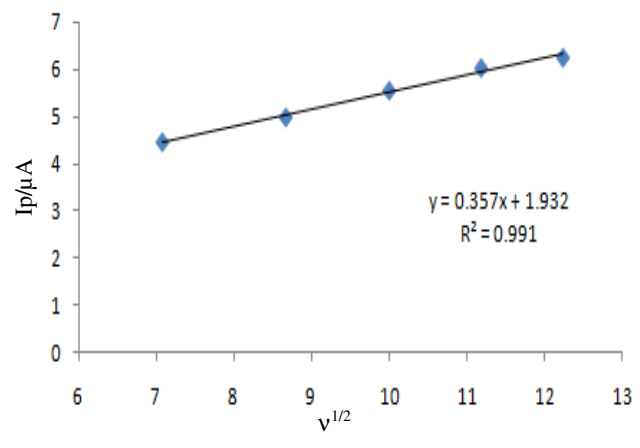

Figure 4. Plot of peak current $(\mathrm{Ip} / \mu \mathrm{A}) v \boldsymbol{~ s .}$ root of scan rates $v^{1 / 2}$

\section{Effect of $p H$}

The peak current closely depends on the $\mathrm{pH}$ of the buffer solution. The cathodic peak current (Ip) reaches maximum value at $\mathrm{pH} 7.0$, after that it decreases further studies were carried out at maximum $\mathrm{pH}$ 13.0. So, the $\mathrm{pH}$ of BR buffer has a significant influence on the reduction of letrozole solution at a concentration of $2.5 \times 10^{-6} \mathrm{~mol} / \mathrm{L}$. The $\mathrm{pH}$ effect was studied in the range 5.4-13 at scan rate of $100 \mathrm{mV} / \mathrm{s}$. The effect of $\mathrm{pH}$ of supporting electrolyte on peak current shows in Figure 5.

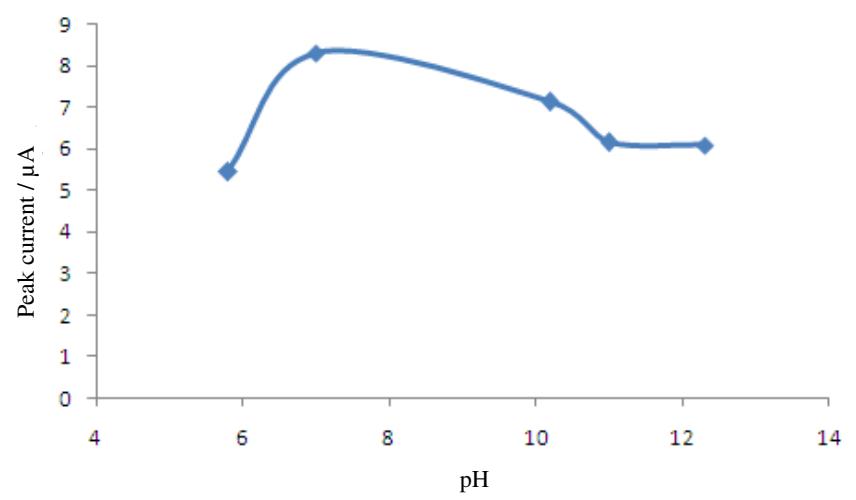

Figure 5. Effect of $\mathrm{pH}$ of medium on cathodic peak current

\section{Square wave cathodic adsorptive stripping voltammetric studies}

The best result with respect to signal evaluation and peak shape accompanied by sharper response was obtained with $\mathrm{BR}$ buffer at $\mathrm{pH}$ 7. This supporting electrolyte was chosen for the subsequent experiments. In order to develop a voltammetric method for the trace element study of the letrozole in pharmaceuticals square wave cathodic adsorptive stripping 
voltammetry (SWCAdSV) was developed. SWCAdSV is effectual and quick electroanalytical technique with well-established advantages, including good discrimination against background current, high sensitivity, substantial speed and low detection limits in alcoholic solution on the basis of electrochemical reduction of letrozole at GCE.

\section{Validation of the procedure}

Validation of the proposed SWCAdSV technique for the analysis of letrozole in pharmaceutical dosages forms was carried out via estimation of the range of linearity, the limit of detection (LOD) and the limit of quantification (LOQ). The applicability of the proposed SWCAdSV procedure as analytical methods for the determination of letrozole was examined by measuring the peak current of stripping mode. The square wave cathodic adsorptive voltammogram of letrozole at concentration over the $3.0 \times 10^{-6} \mathrm{M}$ to $1.0 \times 10^{-6} \mathrm{M}$ are shown in Figure 6. The linear regression equation is expressed as;

$$
\mathrm{Ip}(\mu \mathrm{A})=0.836 \mathrm{C}(\mu \mathrm{M})+3.976(\mu \mathrm{A}) \mathrm{R}^{2}=0.996
$$

The regression plot showed that there is a linear dependence of the current intensity on concentration in SWCAdSV technique over the $3.0 \times 10^{-6} \mathrm{M}$ to $1.0 \times 10^{-6} \mathrm{M}$ shows in Figure 7.

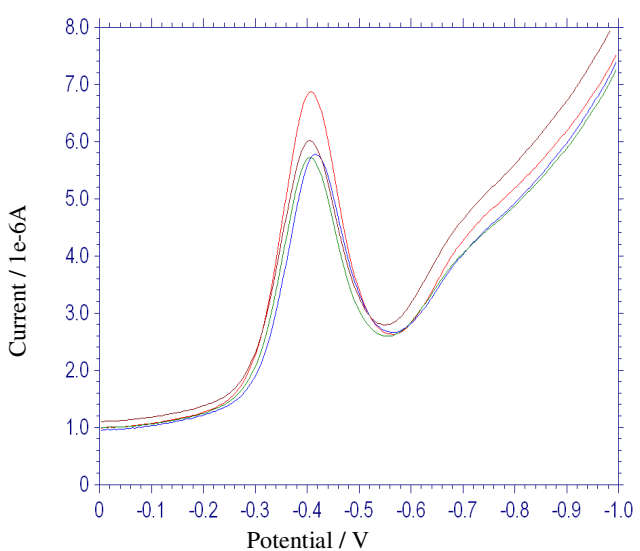

Figure 6. SWCAdS voltammogram of letrozole at different concentrations

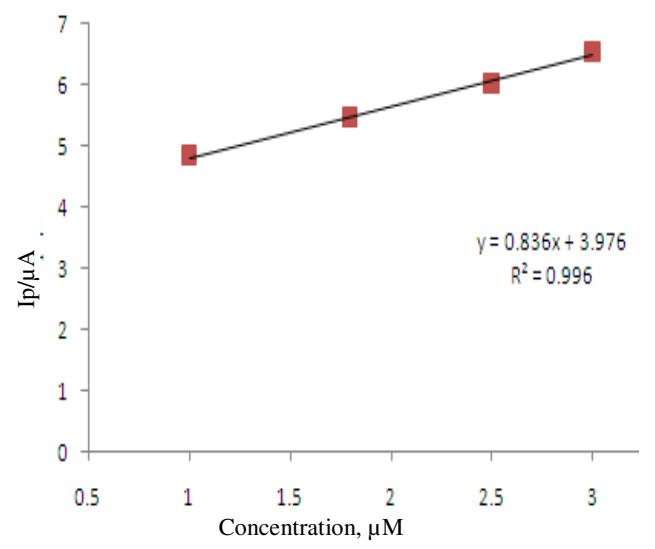

Figure 7. Plot of peak current vs. concentration from SWCAdS voltammogram

\section{Sensitivity / Detection limit}

The limit of detection (LOD) is an important quantity in chemical analysis (Table 1). The LOD is the smallest concentration or amount that can be detected with reasonable certainty for a given analytical procedure. The detection limit was calculated by the equation ${ }^{28,29}$

$$
\mathrm{LOD}=3 \mathrm{SD} / b \text {, }
$$

Where SD is the standard deviation of the peak currents (five runs) and $\mathrm{b}$ is the slope of the calibration curve. The calculated detection limit for the standard solution was $3.89 \times 10^{-7} \mathrm{~mol} \mathrm{~L}^{-1}$.

\section{Quantification limit}

The limit of quantification (LOQ) is the lower limit of concentration for precise quantitative measurements. The quantification limit was examined by the equation

$$
\mathrm{LOQ}=10 \mathrm{SD} / b \text {. }
$$

The limit of quantitation for the standard solution was found to be $12.97 \times 10^{-7} \mathrm{~mol} \mathrm{~L}^{-1}$. 
Table 1. Characterisation data of letrozole calibration plots in BR buffer of $\mathrm{pH}$ value 7.0 for SWCAdSV and DPCAdSV methods

\begin{tabular}{ccc}
\hline Parameters & SWCAdSV & DPCAdSV \\
\hline Linearity range, $\mathrm{M}$ & $3.5 \times 10^{-6}$ to $1 \times 10^{-6}$ & $3.5 \times 10^{-6}$ to $1.0 \times 10^{-6}$ \\
Slope & 0.836 & 0.151 \\
Intercept & 3.976 & 2.125 \\
LOD, $\mathrm{M}$ & $3.89 \times 10^{-7} \mathrm{M}$ & $2.52 \times 10^{-7} \mathrm{M}$ \\
LOQ, $\mathrm{M}$ & $1.297 \times 10^{-6} \mathrm{M}$ & $8.41 \times 10^{-7} \mathrm{M}$ \\
Standard Deviation & 1.085 & 0.0127 \\
Correlation Coefficient $\left(\mathrm{R}^{2}\right)$ & 0.996 & 0.992 \\
\hline
\end{tabular}

Differential pulse cathodic adsorptive stripping voltammetric studies

Furthermore, the validation of the procedure DPCAdSV technique was used. For this, the $\mathrm{pH}$ of solution is 7.0 and potential applied from 0 to $-1.0 \mathrm{~V}$. The linearity range is obtained between -0.3 to $-0.4 \mathrm{~V}$. The differential pulse cathodic adsorptive voltammogram concentration over the $3.0 \times 10^{-6} \mathrm{M}$ to $1.0 \times 10^{-6}$ are shown in Figure 8. The linear regression equation is expressed as;

$$
\mathrm{Ip}(\mu \mathrm{A})=0.151 \mathrm{C}(\mu \mathrm{M})+2.125(\mu \mathrm{A}) \mathrm{R}^{2}=0.992
$$

The regression plot showed that there is a linear dependence of the current intensity on concentration in DPCAdSV technique over the 3.0x10-6 M to 1.0x10-6 M shows in Figure 9. The calculated detection limit for the standard solution was $2.52 \times 10^{-7} \mathrm{~mol} \mathrm{~L}^{-1}$. The limit of quantitation for the standard solution was found to be $8.41 \times 10^{-7} \mathrm{~mol} \mathrm{~L}^{-1}$.

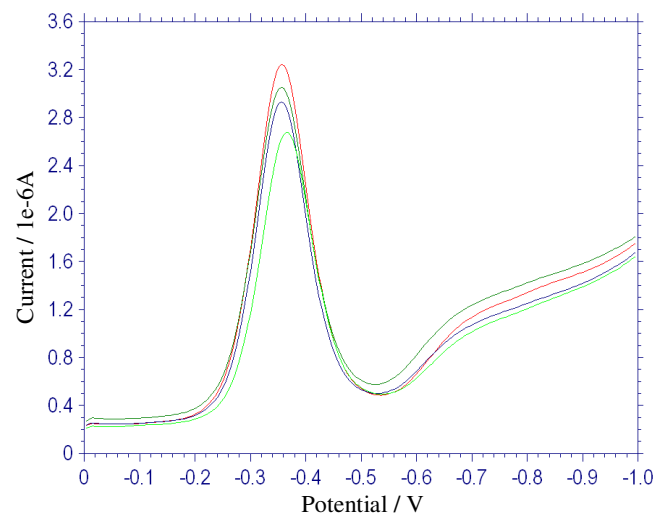

Figure 8. DPCAdS voltammogram of letrozole at different concentrations

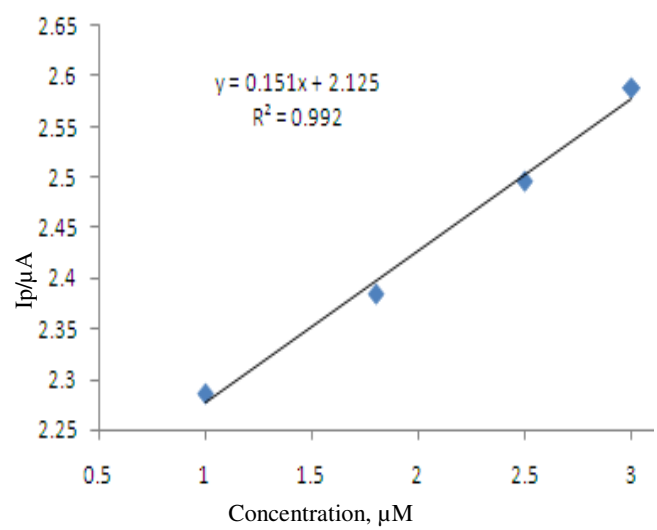

Figure 9. Plot of peak current vs. concentration from DPCAdS voltammogram

\section{Conclusion}

The electrochemical response of letrozole at the surface of glassy carbon electrode was studied by the of CV and SWSV techniques. The electrochemical reduction of letrozole at glassy carbon electrode under the conditions mentioned in this work is diffusion controlled and irreversible process. A validate square wave stripping voltammetric procedure was developed and successfully applied to the estimation of letrozole in pharmaceutical formulation. These methods are reliable, rapid and relatively inexpensive to operate compared with alternative methods. They are suitable for routine analysis in quality control laboratories. 


\section{Acknowledgment}

One of the authors (Anubha Sharma) thankful to University of Rajasthan for Providing Junior Research Fellowship under UGC- UPE (University with Potential Excellency) Scheme wide letter No. RS/2015/UPE-NNF/8948-9000.

\section{References}

1. $\quad$ Birnbaum J, Kahan F M, Kropp H and Macdonald S, Am J Med., 1985, 78(6), 3-21; DOI:10.1016/0002-9343(85)90097-X

2. Rivkin, Drugs Today, 2007, 43, 201-210.

3. Key T, Appleby P, Barnes I and Reeves G, J Nalt Cancer Inst., 2002, 94(8), 606-616; DOI:10.1093/jnci/94.8.606

4. Yager J D and Davidson N E, $N$ Eng $J$ Med., 2006, 354(3), 270-282; DOI:10.1056/NEJMra050776

5. Taichman L Susan, Inglehart Marita R, Giannobile William V, Braun Thomas, Kolenic Giselle and Van Poznak Catherine, J Periodontology, 2015, 86(7), 906-916; DOI:10.1902/jop.2015.140546

6. Omidvari Shapour, Razzaghi Samira, Zamani Ali, Nasrolahi Hamid, Hamedi Sayed Hasan, Mosalaei Ahmad, Ahmadloo Niloofar, Ansari Mansour and Pourahmad Saeedeh, Middle East J Cancer, 2015, 6(1), 35-42.

7. Tamilselvi N, Arivukkarasu R, Antony Ancymol, Anitha T J, Boominathan A, Chandrasekar R and Visakh Deepthi, World J Pharma Res., 2016, 5(1), 884-893.

8. Challa B R, Awen B Z, Chandu B R and Rihanaparveen S, J Chromatogr B, 2011, 879(11-12), 769-775; DOI:10.1016/j.jchromb.2011.02.023

9. Robatel C, Buclin T, Eckert P and Schaller M D, J Pharma Biomed Anal., 2002, 29(1-2), 17-33; DOI:10.1016/S0731-7085(02)00022-5

10. Mrestani Y, Neubert R and Nagel F, J Pharma Biomed Anal., 1999, 20(6), 899-903; DOI:10.1016/S0731-7085(99)00100-4

11. Taniguchi S, Hamase K, Kinoshita A and Zaitsu K, J Chromatogr B, 1999, 727(1-2), 219-226; DOI:10.1016/S0378-4347(99)00005-5

12. Al-Meshal M A, Ramadan M A, Lotfi K M and Shibl A M, J Clin Anal Therap., 1995, 20, 159-163.

13. Kauffmann J M and Viré J C, Anal Chim Acta, 1993, 273(2), 329-337; DOI:10.1016/S0003-2670(01)85500-8

14. Uslu B, Ozkan S A and Sentürk Z, Anal Chim Acta, 2006, 555(2), 341-347; DOI:10.1016/j.aca.2005.09.034

15. Kumari $\mathrm{M}$ and Sharma D K, J Korean Chem Soc., 2011, 55, 50; DOI:10.5012/jkcs.2011.55.1.050

16. Mourya G L, Jhankal K K, Parashar P and Sharma D K, Der Pharm Sinica, 2012, 3(6), 708-714.

17. Uslu B, Dogan B, Ozkan S A and Aboul-Enein H Y, Anal Chim Acta, 2005, 552(1-2), 127-134; DOI:10.1016/j.aca.2005.07.040

18. Wang J, Electroanalytical Chemistry, Wiley-VCH Publication, New York, 167, 2006.

19. Bard A J and Faulkner L R, Electrochemical Methods: Fundamentals and Applications, John Wiley \& Sons. Inc., New York, 2001.

20. Kissinger $\mathrm{P} T$ and Heinman W R, Laboratory Techniques in Electroanalytical Chemistry, Marcel Dekker, New York, 1996.

21. Gosser D K, Cyclic Voltammetry, VCH, New York, 1993. 
22. Ozkan S A, Uslu B and Aboul-Enein H Y, Crit Rev Anal Chem., 2003. 33(3), 155181; DOI:10.1080/713609162

23. Sharma D K, Mourya G L, Jhankal K K, Jones L A and Bhargava S K, Der Pharm Letter, 2012, 4(5), 1599-1606.

24. Jhankal K K, Sharma A, Ramswaroop and Sharma D K, J Pharma Sci Res., 2015, 7(1), 10-16.

25. Sivaprasad M, Dhananjayulu M, and Jayapal M R and Sreedhar N Y, J Anal Bioanal Tech., 2014, 5, 192; DOI:10.4172/2155-9872.1000192

26. Laviron E, Roullier L and Degrand C, J Electroanal Chem., 1980, 112(1), 11-23; DOI:10.1016/S0022-0728(80)80003-9

27. Niranjana E, Naik R R, Kumarswamy B E, Sherigara B S and Jayadevappa H, Int J Electrochem Sci., 2007, 2, 923.

28. Swartz M E and Krull I S, Analytical Method Development and Validation, Marcel Dekker, New York, 1997.

29. Sinha P, Shekhawat A and Sharma D K, Reports Electrochem., 2015, 5, 21-28; DOI:10.2147/RIE.S90750 